\title{
XXIII. On a comparison of the arc and spark spectra of nickel produced under pressure
}

\author{
E.G. Bilham B Sc. A.R.C.Sc.
}

To cite this article: E.G. Bilham B Sc. A.R.C.Sc. (1916) XXIII. On a comparison of the arc and spark spectra of nickel produced under pressure , Philosophical Magazine Series 6, 31:182, 163-170, DOI: $10.1080 / 14786440208635488$

To link to this article: http://dx.doi.org/10.1080/14786440208635488

曲 Published online: 08 Apr 2009.

Submit your article to this journal $₫$

Џll Article views: 2

Q View related articles $๘$ 
XXIII. On a Comparison of the Arc and Spark Spectra of Nickel produced under Pressure. By E. G. Bilmam *, BSc., A.R.C.Sc.

IN a rocent paper $\dagger$, Prof. W. G. Duffield has made a 1 detailed comparison between the results of his investigation of the effects of increase of pressure upon the arc spectrum of nickel $\ddagger$, and those obtained by the present writer $\S$, in which the mode of excitation was the spark between nickel electrodes connected to the secondary coil of a resonance transformer. Many interesting points of similarity are to be observed, but one's attention is immediately arrested by certain very remarkable differences.

The most noteworthy feature of the results is that, whereas the mean displacements towards the red of the lines in the spark spectrum are, upon the whole, in reasonable agreement with the means derived from the arc spectrum-assuming direct proportionality of displacement to increase of pressure, - the displacements in the arc under ten atmospheres pressure are, on the average, about twice as great as in the spark spectrum. An exception is to be observed in the case of lines which broaden slightly but symmetrically under pressure, without reversal, i. e., lines of Class III. in Gale and Adams' notation. These lines appear to suffer approximately equal shifts in the two cases. For other unreversed lines the results are somewhat discordant. This is not surprising when one considers that the diffuseness of the lines under pressure renders the measurements rather uncertain even under the most favourable circumstances.

From the point of view of making a rigorous comparison between the results of the measurements of the displacements produced under the two conditions, it was somewhat unfortunate that the pressure used for my main series of oxperiments (namely, ten atmospheres above the normal pressure) should have happened to coincide with a region where Duffield observed an abnormally high rate of shift per atmosphere. The means at my disposal prohibited the use of pressures much higher than ten atmospheres. Apart from the fact that very radical alterations in the design of

* Communicated by the Author.

$\dagger$ Phil. Mag. Sept. 1915, p. 385.

$\neq$ Duffield, "Effect of Pressure upon Arc Spectra," No. 5, Nickel $\lambda 3450$ to $\lambda$ 5500, Phil. Trans. A 215, p. 205.

$\S$ Bilham, "The Spark Spectrum of Nickel under Moderate Pressures," Phil. Trans. A 214, p. 359. 
the pressure chamber would have been necessary, the difficulty of maintaining a spark under pressure is by no means inconsiderable. The chief source of trouble lay in the rapid disintegration of the electrodes. Working with very small spark gaps, of the order of about a millimetre, a frequent result was that a short circuit was produced by a detached fragment of nickel lodging between the electrodes. Another frequent mishap was that the spark gap rapidly increased in width until a very violent discharge between projecting parts on the outside of the pressure chamber announced the fact that an easier path had been found. Clouding of the window was also a serious source of trouble. Turning to a different aspect of the case, an inspection of the appearance of the photographs produced under a pressure of eleven atmospheres points very forcibly to the conclusion that, in very many instances, measurement of the spectrum "lines" was rapidly approaching the limit of possibility on account. of their diffuseness.

The above considerations will perhaps serve to show that the investigation of spark spectra under high pressures is attended with formidable difficulties, although such data would unquestionably be of great interest and value. Our knowledge of the variation of displacement with pressure in the case of spark spectra is thus limited to comparatively low pressures, and, in attempting to draw any conclusion from the published results, this must be borne in mind.

There can be no doubt, other things being equal, that the most desirable course to take in attempting to estimate the comparative magnitudes of the displacements in the arc and spark spectra, would be to compare measurements actually made under the same pressure in both cases. This procedure, as Duffield has shown, leads to the conclusion that in most cases the shifts in the arc are much higher than in the spark. The question arises as to whether such a conclusion fairly represents the case, when we consider that Duffield's measurements of the shifts in the arc at this pressure are, in general, about double the mean shifts calculated from the measurements made at pressures of from twenty to a hundred atmospheres. Although most investigators have reached the conclusion that the increase of wave length is directly proportional to the increase of pressure, there is, so far as I am aware, no reason for supposing that no departure from this law is possible in a particular instance. Moreover, the possibility exists that the relation between displacement and pressure may be different for the arc and spark spectra of the same element. Duffield has 
shown, further, that the displacement does not depend solely on the applied pressure, but also on the density and temperature gradients, so that there is no à priori reason for expecting strict agreement between the results for arc and spark either in general or in any particular case. One must confess, however, that the discrepancies actually found are of a higher order of magnitude than might be anticipated. Further work on the spark spectrum would undoubtedly be desirable before making anything like a final decision.

Personally, I should hesitate to draw any important conclusions from the fact that my values at five atmospheres increase of pressure are relatively higher than those at ten atmospheres. The smallness of the shifts renders the order of accuracy rather low, and confers additional importance upon the personal error and upon the various causes tending to produce spurious displacements. Among these may be mentioned the effects of granularity in the plates and of lighting during the measurements. The spectrograph used for my experiments was carefully designed to eradicate, as far as possible, displacements due to changes of temperature of the grating or mounting - a fertile source of trouble in all work where the highest precision is essential. Even so, it was found impossible to completely eliminate errors due to this source, except, indeed, by increasing the number of plates for measurement. With exposures of about the same length, more uncertainty would be introduced in the cases where the displacements are smallest, that is, at the lowest pressures; and this applies with equal force to all other sources of error. With a large grating mounted in the Rowland manner, as was employed by Duffield, the temperature effect would undoubtedly be very much larger. Without labouring the point unduly, it will be realized that we have here a cause which might easily account for the whole of the observed discrepancies between Prof. Duffield's displacements at ten atmospheres pressure and my own.

Some further light is thrown upon the question by referring to the results obtained by Humphreys and Mohler* at pressures of $9 \frac{3}{4}, 12 \frac{1}{2}$, and $14 \frac{1}{2}$ atmospheres, and by Humphrey $\dagger$ at the higher pressures of 42,69 , and 101 atmospheres. 'The measurements at the lower pressures are somewhat meagre, but show, on the whole, no large differences from the results obtained by taking the means of the measurements at all pressures. Thus the mean shift per atmosphere of eight lines under pressures up to $14 \frac{1}{2}$ atmospheres is $2 \cdot 0$

* Humphreys and Mobler, Astrophysical Journal, iii. p. 114.

† Humphreys, Astrophysical Journal, xxvi. p. 36. 
thousandths of an Ångström unit, compared with 1.8 from the 42 atmospheres results and 1.9 from all measurements. These lines belong to the types for which Duffield found the greatest discrepancies between the arc and spark measurements at ten atmospheres pressure-namely, those wbich are easily reversed. There is, in general, good agreement amongst the results of the two investigations of the arc. It seems difficult to avoid the conclusion that for some reason Duffield's measurements at ten atmospheres pressure are, on the whole, too high, and, from what has been said with regard to sources of uncertainty, the effect of temperature changes suggests itself as the most likely cause.

\section{Comparison of Arc and Spark Displacements.}

In Table I. are given the mean displacements per atmosphere in the arc found by Humphreys and Duffield respectively, and the averages of the two sets of data, for comparison with the spark displacements. Where only one set of results is available, it is given in brackets under the heading "Mean Displacement in Arc." Duffield's values at ten atmospheres and Humphreys and Mohler's low-pressure values are also given for reference. The class number for each line according to its behaviour in the spark spectrum under pressure is given in column 2.

$$
\text { (Note :- }
$$

\begin{tabular}{|c|c|c|c|c|c|}
\hline Class & T. & & line & which & reverse symmetrically. \\
\hline Class & II. & , & " & " & , unsymmetrically. \\
\hline Class & III. & $"$ & , & ", & $\begin{array}{l}\text { remain bright and fairly } \\
\text { narrow. }\end{array}$ \\
\hline Class & IV. & $"$ & $"$ & " & $\begin{array}{l}\text { remain bright, but are very } \\
\text { much broadened sym- } \\
\text { metrically. }\end{array}$ \\
\hline Class & $\mathrm{V}$. & $"$ & $"$ & $"$ & $\begin{array}{l}\text { are very much broadened } \\
\text { unsymmetrically towards } \\
\text { the red. }\end{array}$ \\
\hline
\end{tabular}

The following classification exhibits a few alterations from that given in my original paper. After a careful reexamination of all my photographs, the lines $3510 \cdot 47$, $3561 \cdot 91,3524 \cdot 87,3739 \cdot 38,3783 \cdot 67$, and $3831 \cdot 87$ have been transferred from Class I. to Class II. The line $4359 \cdot 76$ has been transferred from Class III. to Class V.

lines enhaneed in the spark are indicated by the letter E.) 
Arc and Spark Spectra of Nickel under Pressure. $\quad 167$

Table I.

Mean Displacements per Atmosphere in thousandths A.U.

\begin{tabular}{|c|c|c|c|c|c|c|c|}
\hline \multirow{3}{*}{$\begin{array}{c}\text { Wave-length } \\
\lambda .\end{array}$} & \multirow{3}{*}{ Class. } & \multicolumn{4}{|c|}{ ARC. } & \multirow{3}{*}{$\begin{array}{c}\text { Mean } \\
\text { displace- } \\
\text { ment } \\
\text { per Atm. } \\
\text { in Arc. }\end{array}$} & \multirow{3}{*}{$\begin{array}{c}\text { Mean } \\
\text { displace- } \\
\text { ment } \\
\text { per Atm. } \\
\text { in Spark. }\end{array}$} \\
\hline & & \multicolumn{2}{|c|}{ Humphreys. } & \multicolumn{2}{|c|}{ Duffield. } & & \\
\hline & & $\begin{array}{c}\text { Low } \\
\text { Pressures. }\end{array}$ & $\begin{array}{c}\text { All } \\
\text { Pressures. }\end{array}$ & 10 Atm. & $\begin{array}{c}20-100 \\
\text { Atm. }\end{array}$ & & \\
\hline 1. & 2. & 3. & 4. & 5. & 6. & 7. & 8. \\
\hline $3391 \cdot 21$ & $\ldots$ & $1 \cdot 1$ & $1 \cdot 4$ & $\ldots$ & $\ldots$ & $(1 \cdot 4)$ & \\
\hline $\begin{array}{r}93 \cdot 10 \\
3413 \cdot 64\end{array}$ & $\ldots$ & & 1.5 & $\ldots$ & $\ldots$ & $(1.5)$ & \\
\hline $\begin{array}{r}3413.64 \\
14.96\end{array}$ & $\cdots$ & 1.5 & & $\cdots$ & $\cdots$ & $(1.5)$ & \\
\hline $\begin{array}{l}14 \cdot 96 \\
23 \cdot 80\end{array}$ & $\cdots$ & $1 \cdot 5$ & $\begin{array}{l}1 \cdot 7 \\
2 \cdot 0\end{array}$ & $\cdots$ & $\cdots$ & $(1 \cdot 7)$ & \\
\hline 3371 & $\begin{array}{l}\cdots \\
\cdots\end{array}$ & $\cdots$ & $\begin{array}{l}200 \\
2 \cdot 3\end{array}$ & $\begin{array}{l}\cdots \\
\ldots\end{array}$ & $\ldots$ & $\begin{array}{l}(2 \cdot 0) \\
(2 \cdot 3)\end{array}$ & \\
\hline $37 \cdot 45$ & $\ldots$ & $2 \cdot 2$ & $1 \cdot 9$ & $\ldots$ & $\ldots$ & $(1.9)$ & \\
\hline $46 \cdot 34$ & I. & $\cdots$ & 17 & $\cdots$ & $\ldots$ & $(1 \cdot 7)$ & $1 \cdot 7$ \\
\hline 53.04 & I. & $\ldots$ & $1 \cdot 5$ & $\ldots$ & $\ldots$ & $(1 \cdot 5)$ & $1 \cdot 3$ \\
\hline $54.29 \mathrm{E}$ & IV. & $\cdots$ & $\ldots$ &.. & $\ldots$ & 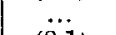 & $1 \cdot \mathbf{a}$ \\
\hline $58 \cdot 59$ & I. & $2 \cdot 1$ & $2 \cdot 1$ & $\ldots$ & $\cdots$ & $(2 \cdot 1)$ & 1.8 \\
\hline 61.78 & I. & $1 \cdot 7$ & $1 \cdot 7$ & $\cdots$ & $\ldots$ & $(1 \cdot 7)$ & $2 \cdot 5$ \\
\hline $67 \cdot 63$ & II. & $\ldots$ & $1 \cdot 5$ & $\cdots$ & $\cdots$ & $(1 \cdot 5)$ & \\
\hline $69 \cdot 64$ & II. & $\ldots$ & $2 \cdot 3$ & $\ldots$ & $\ldots$ & $(2 \cdot 3)$ & \\
\hline 7268 & II. & $\ldots$ & $2 \cdot 0$ & $\cdots$ & $\ldots$ & $(2 \cdot 0)$ & $1 \cdot 4$ \\
\hline $83 \cdot 95$ & II. & $\ldots$ & $\ldots$ & $\ldots$ & $\ldots$ & $\ldots$ & 1.5 \\
\hline $93 \cdot 10$ & I. & $\ldots$ & 20 & $\ldots$ & $\ldots$ & $(2 \cdot 0)$ & $1 \cdot 5$ \\
\hline 3501.00 & II. & $2 \cdot 2$ & $1 \cdot 8$ & $\ldots$ & $(1 \cdot 5)$ & 1.7 & 1.5 \\
\hline $10 \cdot 47$ & II. & & 20 & $\ldots$ & $2 \cdot 6$ & $2 \cdot 3$ & $2 \cdot 2$ \\
\hline $15 \cdot 17$ & I. & $2 \cdot 8$ & $2 \cdot 5$ & $\ldots$ & $\ldots$ & $(2 \cdot 5)$ & $2 \cdot \overline{7}$ \\
\hline $19 \cdot 90$ & II. & $\ldots$ & $1 \cdot 8$ & $\ldots$ & $1 \cdot 4$ & $1 \cdot 6$ & $\overline{1} \cdot 9$ \\
\hline $24 \cdot 65$ & I. & $2 \cdot 4$ & $2 \cdot 3$ & $\ldots$ & $\ldots$ & $(2 \cdot 3)$ & $3 \cdot 0$ \\
\hline $28 \cdot 10$ & II. & $\ldots$ & $\ldots$ & $\ldots$ & $\ldots$ & $\ldots$ & 1.8 \\
\hline $48 \cdot 34$ & II. & $\ldots$ & $2 \cdot 0$ & $\cdots$ & $1 \cdot 2$ & $1 \cdot 6$ & $2 \cdot 1$ \\
\hline $61 \cdot 91$ & II. & $\ldots$ & 1.5 & $\ldots$ & 0.7 & $1 \cdot 1$ & $1 \cdot 1$ \\
\hline $66 \cdot 50$ & I. & $\ldots$ & $2 \cdot 2$ & $\ldots$ & $2 \cdot 1$ & $\overline{2} \cdot 1$ & 20 \\
\hline 71.99 & II. & $\ldots$ & $2 \cdot 4$ & $\ldots$ & $1 \cdot 9$ & $2 \cdot 1$ & 1.8 \\
\hline $76.91 \mathrm{E}$ & IV. & $\ldots$ & & $\ldots$ & & & $\mathbf{8 \cdot 2}$ \\
\hline 88.08 & II. & $\ldots$ & $2 \cdot 2$ & $\ldots$ & $1 \cdot 1$ & 16 & $1 \cdot 4$ \\
\hline 3597.84 & II. & $\ldots$ & $2 \cdot 4$ & $4 \cdot 9$ & $2 \cdot 1$ & $2 \cdot 2$ & $2 \cdot 1$ \\
\hline $3602 \cdot 41$ & II. & $\ldots$ & 20 & $\overline{3} \cdot 1$ & $1 \cdot 8$ & $1 \cdot 9$ & $1 \cdot 6$ \\
\hline 09.44 & I. & $\ldots$ & 1.8 & 29 & $1 \cdot 0$ & $1 \cdot 4$ & 16 \\
\hline $10 \cdot 60$ & II. & $\ldots$ & $2 \cdot 4$ & $6 \cdot 4$ & $2 \cdot 2$ & $2 \cdot 3$ & 26 \\
\hline $12 \cdot 86$ & II. & $\ldots$ & $2 \cdot 0$ & $4 \cdot 4$ & $1 \cdot 4$ & 1.7 & $1 \cdot 6$ \\
\hline 19.52 & I. & $\ldots$ & 1.6 & $4 \cdot 7$ & $2 \cdot 6$ & $2 \cdot 1$ & 1.8 \\
\hline $24 \cdot 87$ & II. & $\ldots$ & 1.5 & $3 \cdot 4$ & 0.8 & $1 \cdot 1$ & 07 \\
\hline $35 \cdot 07$ & III. & $\ldots$ & & 47 & $1 \cdot 5$ & $(1 \cdot \overline{5})$ & $5 \cdot 1$ \\
\hline $62 \cdot 10$ & III. & $\ldots$ & $1 \cdot 3$ & $3 \cdot 7$ & $1 \cdot 1$ & $1 \cdot 2$ & $3 \cdot 5$ \\
\hline $64 \cdot 24$ & II. & $\ldots$ & $1 \cdot 6$ & $4 \cdot 8$ & $1 \cdot 7$ & $1 \cdot 7$ & $2 \cdot 2$ \\
\hline 69.39 & II. & $\ldots$ & & $3 \cdot 1$ & $1 \cdot 3$ & $(1 \cdot 3)$ & $1 \cdot \overline{2}$ \\
\hline $70 \cdot 57$ & II. & $\ldots$ & $1 \cdot 3$ & $3 \cdot 9$ & $2 \cdot 1$ & 1.8 & $2 \cdot 5$ \\
\hline $74 \cdot 20$ & iJ. & $\ldots$ & 1.0 & 42 & $1 \cdot 7$ & $1 \cdot 4$ & $1 \cdot 9$ \\
\hline 88.58 & II. & $\ldots$ & 1.0 & $3 \cdot 7$ & $1 \cdot 8$ & $1 \cdot 4$ & $2 \cdot 0$ \\
\hline $94 \cdot 07$ & III. & $\ldots$ & $\ldots$ & $2 \cdot 6$ & $1 \cdot 3$ & $(1 \cdot 3)$ & $2 \cdot 5$ \\
\hline
\end{tabular}


Mr. E. G. Bilham on a Comparison of the

\begin{tabular}{|c|c|c|c|c|c|c|c|}
\hline \multirow{3}{*}{$\begin{array}{c}\text { Ware-length } \\
\text { A. }\end{array}$} & \multirow{3}{*}{ Class. } & \multicolumn{4}{|c|}{ Anc. } & \multirow{3}{*}{$\begin{array}{c}\text { Mean } \\
\text { displace- } \\
\text { ment. } \\
\text { per Atm. } \\
\text { in Arc. }\end{array}$} & \multirow{3}{*}{$\begin{array}{c}\text { Mean } \\
\text { displace- } \\
\text { ment. } \\
\text { per Atm: } \\
\text { in Spark. }\end{array}$} \\
\hline & & \multicolumn{2}{|c|}{ Humphreys. } & \multicolumn{2}{|c|}{ Duffield. } & & \\
\hline & & $\begin{array}{c}\text { Low } \\
\text { Pressures. }\end{array}$ & $\begin{array}{c}\text { All } \\
\text { Pressures. }\end{array}$ & $10 \mathrm{Atm}$. & $\begin{array}{c}20-100 \\
\text { Atm. }\end{array}$ & & \\
\hline 1. & 2. & 3. & 4. & 5. & 6. & 7. & 8. \\
\hline $3722 \cdot 63$ & Il. & $\cdots$ & 1.6 & $\ldots$ & $2 \cdot 2$ & $1 \cdot 9$ & $2 \cdot 9$ \\
\hline 36.94 & II. & $\ldots$ & $1 \cdot 2$ & $\ldots$ & $1 \cdot 6$ & $1 \cdot 4$ & 10 \\
\hline $39 \cdot 38$ & II. & $\ldots$ & $\ldots$ & & $1 \cdot 2$ & $(1 \cdot 2)$ & $1 \cdot 0$ \\
\hline $69 \cdot 62 \mathrm{E}$ & IV. & $\ldots$ & $\ldots$ & 4.0 & $1 \cdot 4$ & $(1 \cdot 4)$ & $7 \cdot 7$ \\
\hline $75 \cdot 71$ & II. & $\ldots$ & 13 & $1 \cdot 0$ & 1.5 & 1.4 & $2 \cdot 2$ \\
\hline $83 \cdot 67$ & II. & $\ldots$ & 0.9 & $1 \cdot 3$ & $1 \cdot 3$ & $1 \cdot 1$ & $1 \cdot 6$ \\
\hline $3807 \cdot 30$ & II. & $\ldots$ & $1 \cdot 1$ & $3 \cdot 0$ & 1.5 & $1 \cdot 3$ & $1 \cdot 8$ \\
\hline $31 \cdot 87$ & II. & $\cdots$ & $\ldots$ & $3 \cdot 2$ & $1 \cdot 8$ & $(1 \cdot 8)$ & 36 \\
\hline $4970 \mathrm{E}$ & IV. & $\cdots$ & & 00 & 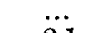 & & $14 \cdot 9$ \\
\hline $58 \cdot 40$ & I. & $\cdots$ & $1 \cdot 7$ & $3 \cdot 9$ & $2 \cdot 1$ & $1 \cdot 9$ & $2 \cdot 1$ \\
\hline $3972 \cdot 31$ & III. & $\cdots$ & $1 \cdot 1$ & $1 \cdot 2$ & 0.8 & $1 \cdot 0$ & 28 \\
\hline $73 \cdot 70$ & V. & $\ldots$ & $2 \cdot 0$ & $4 \cdot 4$ & 1.9 & $2 \cdot 0$ & $5 \cdot 8$ \\
\hline $4121 \cdot 48$ & III. & $\ldots$ & $\ldots$ & $3 \cdot 9$ & $1 \cdot 7$ & $(1 \cdot 7)$ & $2 \cdot 6$ \\
\hline $42 \cdot 47$ & III. & $\cdots$ & $\ldots$ & 10.5 & & & $3 \cdot 2$ \\
\hline $4288 \cdot 20$ & V. & $\cdots$ & $\cdots$ & $16 \cdot 2$ & $10 \cdot 9$ & $(10 \cdot 9)$ & $12 \cdot 1$ \\
\hline $\left.\begin{array}{r}4330 \cdot 85 \\
31.78\end{array}\right\}$ & III. & $\cdots$ & $2 \cdot 1$ & $6 \cdot 3$ & $3 \cdot 0$ & $2 \cdot 6$ & $4 \cdot 4$ \\
\hline $59 \cdot 76$ & v. & $\cdots$ & & $11 \cdot 5$ & $12 \cdot 2$ & $(12 \cdot 2)$ & $10 \cdot 6$ \\
\hline $4401 \cdot 70$ & V. & $\ldots$ & $4 \cdot 8$ & $11 \cdot 6$ & $12 \cdot 0$ & $8 \cdot 4$ & $10 \cdot 2$ \\
\hline $4459 \cdot 25$ & V. & $\ldots$ & 6.2 & $10 \cdot 2$ & $10 \cdot 9$ & $8 \cdot \overline{6}$ & $9 \cdot 3$ \\
\hline $62 \cdot 65$ & V. & $\ldots$ & & $12 \cdot 3$ & $9 \cdot 5$ & $(9 \cdot 5)$ & $9 \cdot 9$ \\
\hline $70 \cdot 61$ & V. & $\ldots$ & $8 \cdot 5$ & $12 \cdot 4$ & $11 \cdot 0$ & $9 \cdot 7$ & $8 \cdot 9$ \\
\hline $4520 \cdot 20$ & & $\ldots$ & 1.8 & $3 \cdot 1$ & $1 \cdot 7$ & $1 \cdot 8$ & \\
\hline $92 \cdot 69$ & V. & $\ldots$ & 8.5 & $14 \cdot 1$ & $10 \cdot 3$ & $9 \cdot 4$ & $11 \cdot 8$ \\
\hline $4600 \cdot 51$ & IV. & $\ldots$ & $11 \cdot 3$ & $13 \cdot 8$ & $9 \cdot 3$ & 103 & \\
\hline $05 \cdot 15$ & V. & $\ldots$ & $7 \cdot 8$ & $12 \cdot 0$ & $9 \cdot 5$ & $8 \cdot 7$ & \\
\hline 48.82 & V. & $\ldots$ & $8 \cdot 1$ & $14 \cdot 0$ & $11 \cdot 4$ & $9 \cdot 8$ & \\
\hline $86 \cdot 39$ & III. & $\ldots$ & 80 & $18 \cdot 4$ & $11 \cdot 7$ & $9 \cdot 4$ & \\
\hline $4714 \cdot 59$ & V. & $\cdots$ & 67 & $17 \cdot 1$ & $11 \cdot 1$ & $8 \cdot 9$ & \\
\hline $56 \cdot 70$ & v. & $\ldots$ & $7 \cdot 2$ & $15 \cdot 7$ & $11 \cdot 3$ & $9 \cdot 3$ & \\
\hline
\end{tabular}

The mean shifts for the lines in each class have been computed for comparison with the values found by Duffield for the arc. Only lines figuring in both investigations have been included.

TABLE II.

\begin{tabular}{|c|c|c|c|c|}
\hline Class. & $\begin{array}{c}\text { Number } \\
\text { of } \\
\text { Lines. }\end{array}$ & \multicolumn{2}{|c|}{ Mean displacement per Atmosphere. } & $\begin{array}{c}\text { Arc (Duffield). } \\
\text { Ratio } \\
\text { Spark: Arc. }\end{array}$ \\
\hline I. & 4 & 1.95 & Spark. & 1.88 \\
II. & 24 & 1.60 & 1.85 & 0.96 \\
III. & 6 & 1.57 & 3.48 & 1.16 \\
IV. & 1 & 1.4 & 7.7 & 5.22 \\
V. & 8 & 9.84 & 9.83 & 1.00 \\
\hline
\end{tabular}


Arc and Spark Speitra of Nirkel under Pressure.

If Humphreys' data are included in obtaining the means for the arc, the results are only slightly modified as in Table III.

TABLE III.

\begin{tabular}{|c|c|c|c|c|}
\hline Class. & $\begin{array}{c}\text { Number } \\
\text { of } \\
\text { Lines. }\end{array}$ & \begin{tabular}{c} 
Mean Displacement per Atmosphere. \\
\cline { 3 - 5 }
\end{tabular} & $\begin{array}{c}\text { Are (Humphreys } \\
\text { and Duffield). }\end{array}$ & $\begin{array}{c}\text { Spark. } \\
\text { Ratio } \\
\text { Spark : Arc. }\end{array}$ \\
\hline I. & 11 & 1.94 & $2 \cdot 00$ & 1.03 \\
II. & 25 & 1.64 & 1.84 & 1.12 \\
III. & 6 & 1.55 & 3.48 & 2.25 \\
IV. & 1 & 1.4 & 7.7 & $5 \cdot 50$ \\
V. & 8 & 8.84 & 9.83 & 1.11 \\
\hline
\end{tabular}

From an inspection of Tables II. and III. we arrive at the interesting conclusion that the arc and spark shifts are, on the whole, very nearly equal for lines in Classes I., II., and V., but for lines in Class III. the spark displacement is rather more than twice that in the arc. The values for Class IV. rest upon the results for a single line, so that the probability of error is too great to permit of any important conclusions being drawn. It is a significant fact that certain lines in Class $V$. show signs of reversal in the spark under a pressure of eleven atmospheres. For example, the reversal of the line $4401 \cdot 77$, a typical specimen of this class, can be distinctly seen in Plate $i$. of my original paper. In the are this line is given by Duffield as suffering immense unsymmetrical broadening, without reversal even at the highest pressures. If we regard the continuous spectrum, which is so prominent in the more refrangible region of the spark spectrum, as being due to immense broadenings of lines of Classes I. and II. it is evident that Class V. lines have something in common with those of Classes 1. and II., although at first sight nothing could appear more dissimilar.

The view I have taken-namely, that Duffield's displacements at ten atmospheres pressure are uniformly too highthus leads us to the conclusion that the behaviour of lines easily reversed, or tending to reverse, is approximately the same whether developed in the arc or spark under pressure. Phil. Mag. S. 6. Vol. 31. No. 182. Fel. 1916. N 
Abnormalities or discrepancios are exhibited by unreversed lines. It will be observed that this result is exactly the opposite of that reached by Duffield's analysis of the data, and supported by the theory he gives concerning the part played by the density and temperature gradients. It remains for further investigation to decide whether this view is correct. The whole question turns very largely upon the reality of an abnormally large rate of displacement with pressure in the nickel arc at relatively low pressures; and confirmation of Prof. Duffield's conclusion may be regarded as one of the most pressing problems in this branch of spectroscopy.

The part played by the temperature and density gradients in determining the position of the maximum of emission or absorption in a spectrum line is a problem which is becoming increasingly more prominent with every fresh advance in this line of investigation. It must be confessed that we are still far from a complete interpretation of all the manifold phenomena which present themselves. All that we can really be sure about at present is that the measured displacement is made up of a component directly due to the increase of pressure and probably proportional to it, together with a component of uncertain magnitude which has its origin in the changes in the structure of the line due to the alterations of the conditions prevailing in the source of emission. To what extent it may be possible eventually to disentangle the two components one cannot at present say. Meanwhile, as Dr. Royds * has recently remarked, the most valuable method of attack appears to be that of the electric furnace, in which the vapour density is likely to be influenced by pressure to a much less extent than in the arc or spark. In any case, the recognition of the existence of these pbenomena is of the first importance, not only in interpreting existing results, but also in determining the most profitable directions for future research.

Kew Observatory,

November 1915.

* Kodaikanal Observatory Bulletin, No, xliii. 